\title{
INSTABILIDADE NO CENÁRIO SOCIOECONÔMICO E POLÍTICO NO BRASIL A PARTIR DE 2014: CONTRACHOQUE DO PETRÓLEO, MUDANÇAS NO MARCO REGULATÓRIO E OPERAÇÃO LAVA JATO
}

\author{
Leandro Campos Azevedo ${ }^{1}$ \\ ORCID:https://orcid.org/0000-0002-7529-0415 \\ Romeu e Silva Neto ${ }^{2}$ \\ ORCID:https://orcid.org/0000-0001-7061-8824 \\ Recebido em: 09/04/2021 \\ Publicado em: 30/06/2021
}

\section{RESUMO}

Este artigo se propõe a analisar a instabilidade no cenário socioeconômico e político do Brasil com o contrachoque do petróleo de 2014, tendo-se como referência os fatores que influenciaram a volatilidade dos preços do petróleo na época, as mudanças no marco regulatório de exploração e produção de petróleo no País e a crise política derivada, entre vários fatores, da Operação Lava Jato. A pesquisa tem caráter exploratório e descritivo quando visa identificar e descrever os fatores que influenciaram a crise, e caráter explicativo quando busca a compreensão dos impactos dos fatores sobre as oscilações do valor do petróleo e sobre a instabilidade do cenário socioeconômico e político. Fez-se uma pesquisa bibliográfica em trabalhos que abordam o setor de petróleo, a geopolítica do petróleo, a regulação das atividades de extração e produção do petróleo no Brasil e a Operação Lava Jato. Os resultados do artigo apontam que a volatilidade é derivada de três fatores principais: as forças de oferta e demanda, fatores geopolíticos e a financeirização do petróleo e que a crise política tem como causas principais, entre vários fatores, as mudanças no marco regulatório do petróleo no país e a Operação Lava Jato. Tais fatores conjugados, por sua vez, influenciaram a crise da Petrobras, obrigando-a a reduzir seu escopo de atuação na cadeia produtiva e, por conseguinte, reduzindo sua capacidade como instrumento propulsor da política de conteúdo local do país, fundamental para o desenvolvimento socioeconômico nacional e das regiões produtoras.

PALAVRAS-CHAVE: Crise do petróleo de 2014; Indústria do petróleo; Geopolítica do petróleo; Marco regulatório do petróleo; Operação Lava Jato.

\section{INSTABILITY IN THE SOCIOECONOMIC AND POLITICAL SCENARIO IN BRAZIL FROM 2014 ONWARDS: OIL COUNTERSHOCK, CHANGES IN THE REGULATORY FRAMEWORK, AND LAVA JATO OPERATION}

\footnotetext{
${ }^{1}$ Professor universitário de Graduação e Pós-Graduação. LecionanaUniversidadeCandido Mendes -UCAM CAMPOS.

${ }^{2}$ Professor Titular do IFF - Instituto Federal Fluminense junto ao PPEA - Programa de

PósGraduaçãoemEngenhariaAmbiental e aoMestradoemSistemasAplicados à Engenharia e Gestão (SAEG).
} 


\begin{abstract}
This article analyzes the instability in the socioeconomic and political scenario in Brazil with the 2014 oil countershock in reference to the factors that influenced the volatility of oil prices at that time, the changes in the regulatory framework of oil exploration and production in the country, and the political crisis resulting, among many others, from the Lava Jato Operation.The research has an exploratory and descriptive character as it aims at identifying and describing what influenced the crisis, and an explanatory character in order to understand the impacts of the factors on the oscillations of the oil value and on the instability of the socioeconomic and political scenario. A bibliographical research was conducted on works related to the oil sector, oil geopolitics, regulation of oil extraction and production activities in Brazil, and the Lava Jato Operation.Results show that the volatility is derived from three main factors: supply and demand forces, geopolitical factors, and the financialization of oil, and that the political crisis has as its main causes, along with a number of other factors, the changes in the oil regulatory framework in the country and the Lava Jato Operation.These combined factors, in turn, influenced the Petrobras crisis, leading the company to narrow its performance in the production chain and, as a result, reducing its capacity as an instrument to propel the country's local content policy, which is fundamental for the socioeconomic development of the country and of the producing regions.
\end{abstract}

KEYWORDS: 2014 oil crisis; Oil industry; Oil geopolitics; Oil regulatory framework; The Lava Jato Operation.

\title{
INESTABILIDAD EN EL ESCENARIO SOCIOECONÓMICO Y POLÍTICO DE BRASIL A PARTIR DE 2014: REVÉS PETROLERO, CAMBIOS EN EL MARCO REGULATORIO Y OPERACIÓN LAVA JATO
}

\section{RESUMEN}

El presente artículo es un análisis de la inestabilidad en el escenario socioeconómico y político de Brasil con el revés petrolero de 2014, considerando los factores que influyeron en la volatilidad de los precios del petróleo en ese momento, los cambios en el marco regulatorio de la exploración y producción de petróleo en el país y la crisis política derivada, entre varios factores, de la Operación Lava Jato. La investigación es de carácter exploratorio y descriptivo al tratar de identificar y describir los factores que influyeron en la crisis, y de carácter explicativo al buscar comprender los impactos de los factores en las oscilaciones del valor del petróleo y en la inestabilidad del escenario socioeconómico y político. Se ha realizado una investigación bibliográfica sobre obras que tratan el sector del petróleo, la geopolítica del petróleo, la regulación de las actividades de extracción y producción de petróleo en Brasil y la Operación Lava Jato. Los resultados del artículo indican que la volatilidad se deriva de tres factores principales: las fuerzas de la oferta y la demanda, los factores geopolíticos y la "financiarización" del petróleo, y que la crisis política tiene como causas principales, entre varios factores, los cambios en el marco regulatorio del petróleo en el país y la Operación Lava Jato. Estos factores combinados, a su vez, influyeron en la crisis de Petrobras, obligándola a reducir su ámbito de actuación en la cadena de producción y, en consecuencia, reduciendo su capacidad como instrumento para impulsar la política de contenido local del país, esencial para el desarrollo socioeconómico nacional y de las regiones productoras.

PALABRAS CLAVE: Crisis del petróleo de 2014; Industria del petróleo; Geopolítica del petróleo; Marco regulatorio del petróleo; Operación Lava Jato. 


\section{INTRODUÇÃO}

O petróleo emergiu, especialmente após a $2^{\mathrm{a}}$ Guerra Mundial, como matéria-prima indispensável ao desenvolvimento econômico das nações e como elemento estratégico para seu fortalecimento na geopolítica internacional. Assim, passou a ser objeto de intensas disputas por interesses de domínio e de produção em diversas regiões produtoras do mundo. Seu valor passou a sofrer variações que, para serem explicadas, seria necessário ir além das tradicionais explicações baseadas nas oscilações na oferta e demanda do produto. Fatores geopolíticos passaram a ser fundamentais para essa compreensão. E essa volatilidade passou a provocar impactos diretos na instabilidade socioeconômica e política das nações.

Este artigo se propõe a analisar a instabilidade no cenário socioeconômico e político do Brasil com a crise do petróleo de 2014, denominada neste artigo de 'contrachoque do petróleo de 2014', um dos mais atingidos, tendo-se como referência os fatores que influenciaram a volatilidade dos preços do petróleo na época, as mudanças no marco regulatório de exploração e produção de petróleo no país e a crise política derivada, dentre vários fatores, da Operação Lava Jato. A análise desse complexo cenário visa, por sua vez, buscar a compreensão dos impactos nas grandes petroleiras, em especial na Petrobras, e nas para-petroleiras, com desdobramentos em toda a cadeia produtiva do petróleo, afetando a continuidade da política de conteúdo nacional utilizada pelo governo brasileiro como estratégia de desenvolvimento econômico nacional e das regiões produtoras, em especial no estado do Rio de Janeiro, maior produtor nacional.

Compreender esse cenário é fundamental para entender os desafios que o país e o estado têm a enfrentar com o enfraquecimento de sua endógena cadeia produtiva do petróleo e suas consequências sobre o processo de desenvolvimento econômico.

Para entender o contrachoque do petróleo de 2014 e seus impactos no Brasil, faz-se fundamental analisar o período a partir do final dos anos 1990, em especial, a partir de 1997 com a publicação da Lei No. 9.478, a chamada Lei do Petróleo. A partir desse recorte temporal, este trabalho busca identificar os principais fatores que influenciaram a volatilidade nos preços do petróleo e, por conseguinte, que impactaram a instabilidade do cenário socioeconômico e político do país.

A hipótese defendida neste trabalho, a partir da análise de artigos e relatórios especializados, é de que essa volatilidade é derivada de três fatores principais: as forças de oferta e demanda, os fatores geopolíticos e a financeirização do petróleo (RIBEIRO et al., 2018; COLOMBINI, 2020; FURTADO, 2019) e que a crise política tem como causas 
principais, dentre vários fatores, as mudanças no marco regulatório do petróleo no país e a Operação Lava Jato. Tais fatores conjugados, por sua vez, influenciaram a crise da Petrobras, obrigando-a a reduzir seu escopo de atuação na cadeia produtiva e, por conseguinte, reduzindo sua capacidade como instrumento propulsor da política de conteúdo local do país, fundamental para o desenvolvimento socioeconômico nacional e das regiões produtoras.

A investigação tem caráter exploratório e descritivo quando visa identificar e descrever os fatores que influenciaram a crise, e caráter explicativo quando busca a compreensão dos impactos dos fatores sobre as oscilações do valor do petróleo e sobre a instabilidade do cenário socioeconômico e político. Fez-se uma pesquisa bibliográfica no Portal de Periódicos da CAPES (Base Scopus) e no Google Acadêmico em trabalhos que abordam o setor de petróleo, a geopolítica do petróleo, a regulação das atividades de extração e produção do petróleo no Brasil e a Operação Lava Jato. Também fez-se uma pesquisa documental em relatórios, boletins e notas técnicas de agências e organizações ligados ao setor de petróleo como a Agência Nacional do Petróleo (ANP), Instituto Brasileiro do Petróleo, Gás e Biocombustíveis (IBP) e outros.

Em relação ao processo de coleta de dados, o trabalho se apoiou em dados secundários relativos a indicadores de crescimento econômico no Instituto Brasileiro de Geografia e Estatística (IBGE), evolução do preço do barril do petróleo (brent) no mercado internacional e evolução da produção de petróleo no Brasil por ambiente de produção na ANP.

$\mathrm{O}$ artigo tem quatro seções. Esta introdução, que apresenta a contextualização do tema, os objetivos e a metodologia da pesquisa. A segunda seção apresenta um breve histórico sobre a evolução da indústria de petróleo e gás no país, fundamental para se compreender a cronologia dos principais marcos do setor. A terceira seção trata do cerne do trabalho que é a instabilidade no cenário socioeconômico e político nacional a partir do contrachoque do petróleo de 2014 e seus principais fatores indutores: as forças de oferta e demanda, os fatores geopolíticos, a financeirização do petróleo, a Operação Lava Jato e, por fim, a crise da Petrobras. Na quarta e última seção, são apresentadas as conclusões do artigo.

\section{UM BREVE HISTÓRICO DA INDÚSTRIA DO PETRÓLEO E GÁS NATURAL NO BRASIL}

No cenário mundial, o petróleo e seus derivados têm grande importância estratégica para o desenvolvimento das nações. $\mathrm{O}$ dinamismo das atividades de exploração e produção 
do petróleo e gás, com sua capacidade de arrasto ao longo de cadeia produtiva e seus impactos sobre outros setores econômicos, como serviços, comércio e construção civil, assim como suas rendas de royalties e participações especiais para a união, estados e municípios, são determinantes para a dinamização econômica de uma região.

No Brasil, o petróleo se tornou, a partir da década de 1950, a principal fonte de energia primária que alimenta o consumo energético nacional do setor moderno industrial do país. A criação da Petrobras, em 1953,teve a finalidade de desenvolver a produção de petróleo para atender às necessidades nacionais.

Embora inicialmente, a partir dos anos 1960, a Petrobras tenha priorizado as atividades de refino, com as crises do petróleo de 1973 e 1979 que elevaram significativamente o preço do petróleo importado, a Petrobras passou a priorizar o upstream, numa estratégia bem-sucedida de desenvolver a produção do petróleo em águas profundas e ultraprofundas. (FURTADO, 2019)

Os resultados dessa estratégia foram sentidos no início da década de 1980, quando a produção nacional de petróleo e de gás natural offshore cresceu expressivamente (ver Gráfico 1). Essa expansão da produção interna percorreu fases distintas, sendo que um primeiro salto (denominado neste trabalho de Fase 1) aconteceu na primeira metade dos anos 1980, para se estabilizar logo em seguida. Nesse período ocorreram os primeiros desenvolvimentos do petróleo offshore ainda em águas rasas (abaixo de 400 metros de profundidade). O segundo salto (Fase 2) ocorreu a partir da segunda metade dos anos 1990 e se apoiou no petróleo em águas profundas (FURTADO, 2009). Esse salto se estendeu até osanosiniciaisda década 2010, quando apresentou declínio em função da crise do contrachoque do petróleo de 2014, que afetou a produção na Bacia de Campos. Finalmente, em seguida, a produção de petróleo foi retomada, apoiando-se, sobretudo, na expansão da produção do pré-sal.

Gráfico 1 - Produção Brasileira de Petróleo e Gás Natural 


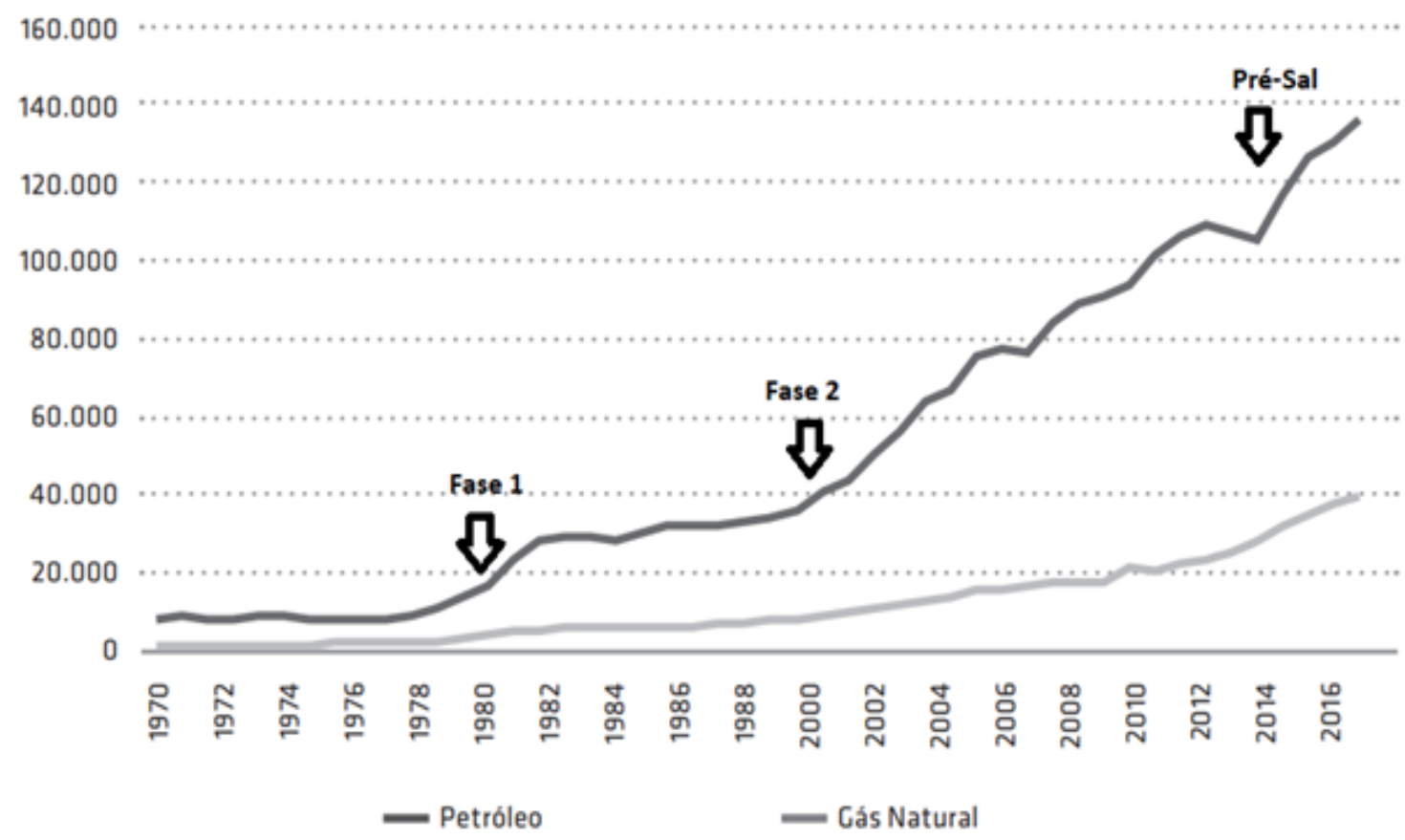

Fonte: adaptado de EPE (2018) apud Furtado (2019)

Com o advento da Lei do Petróleo, Lei 9.478 de 06/08/1997, ainda dentro do que se denominou neste trabalho de Fase 1, mudanças começaram a ocorrer. O monopólio da exploração foi suprimido e criada uma agência reguladora, a Agência Nacional do Petróleo, hoje Agência Nacional do Petróleo e Biocombustíveis (ANP), responsável por normatizar, contratar e fiscalizar as atividades do setor.

A partir do final dos anos 1990, já na Fase 2, a produção cresceu quase que exponencialmente. A Bacia de Campos, em franca expansão, registrou em 1999 a marca histórica de produção de 1 milhão de barris de petróleo por dia, mesmo ano em que a Petrobras bateu o recorde mundial de produção de petróleo em águas profundas (NADER, 2009).

No final desta década, destaca-se também a repartição dos royalties e participações especiais para estados e municípios confrontantes e limítrofes do litoral (PESSANHA, 2015). Além da ANP, criou-se o Conselho Nacional de Política Energética (CNPE), órgão responsável por formular as políticas públicas de energia para todo o território nacional. (NADER, 2009).

Em meados dos anos 2000, o Brasil alcançou a tão almejada autossuficiência no abastecimento do mercado interno. Em 2006, confirmou-se a descoberta das reservas na camada do pré-sal pela Petrobras no litoral brasileiro.Contudo, a autossuficiência regrediu ostensivamente no começo dos anos 2010 em decorrência da inflexão na produção interna 
(observada no Gráfico 1, do ano 2010 a 2013) e da expressiva expansão do consumo. (FURTADO, 2019)

Ainda segundo o referido autor, esse retrocesso iniciou um processo de recuperação, em função do aumento da produção de petróleo e gás natural impulsionada pelo pré-sal a partir do desenvolvimento de tecnologias nacionais de exploração e produção em águas profundas e ultraprofundas.

A partir de 2014, observou-se o aumento da oferta interna influenciada pela produção do pré-sal, a redução da demanda causada pela crise econômica dos anos iniciais de 2010 e a queda abrupta do preço do petróleo no mercado internacional, objeto central de análise desse trabalho.

Em 2017, a produção do pré-sal chegou a 47\% da produção nacional, com uma produção de aproximadamente 1,588 milhão de barris de óleo equivalente por dia (MMboe/d). Atualmente, segundo o Boletim da ANP de janeiro de 2021, a produção do présal corresponde a 70,5 \% do total produzido no Brasil. A produção do pré-sal, oriunda de 119 poços, foi de 2,074 MMbbl/d depetróleo e 88,3 $\mathrm{MMm}^{3} / \mathrm{d}$ de gás natural, totalizando 2,629 MMboe/d. (ANP, 2021)

\section{O NOVO MARCO REGULATÓRIO E OS REGIMES DE EXPLORAÇÃO E PRODUÇÃO DE PETRÓLEO NO BRASIL}

Antes de passar para a análise da instabilidade no cenário socioeconômico e político no Brasil a partir de 2014, com o contrachoque do petróleo, faz-se necessário compreender o novo marco regulatório do setor de óleo e gás a partir de 2009.

Segundo Pacheco (2021), esse novo marco regulatório trouxegrandes mudanças para o panorama político e econômico do Brasil. A principal proposta da nova lei é a alteração da forma de licitação para as empresas exploradoras, mais precisamente do Regime de Concessão para o Regime de Partilha de Produção.

Entendera evolução da legislação do petróleo no país faz-se importante a fim de que seja possível entender as motivações do governo brasileiro em fazer uma alteração tão importante na lei vigente e entender os impactos dessas alterações no contexto socioeconômico brasileiro.

Segundo Pacheco (2021), em 1953, Getúlio Vargas assinou a Lei No. 2004, que instituiu o monopólio estatal da pesquisa e lavra, refino e transporte do petróleo e seus derivados e criou a Petróleo Brasileiro S.A - Petrobras. O monopólio estatal passou a ser 
exercido pela Petrobras e pelo Conselho Nacional do Petróleo, cabendo a este Conselho orientar e fiscalizar as atividades decorrentes do monopólio, e à Petrobras e suas subsidiárias, executar o monopólio.

A revisão da Constituição de 1988, realizada em 1995, compreendeu a abertura econômica nas áreas de petróleo e gás natural. Uma emendaconstitucionalpassou a permitir que a união contratasse outras empresas, estatais ou privadas, para executar as atividades anteriormente monopolizadas, mediante a celebração de contrato. (PACHECO, 2021)

Conforme já mencionado anteriormente, em 1997, foi sancionada a Lei $N^{\circ} 9.478$, chamada de 'a Lei do Petróleo', que marcou a abertura do setor para a exploração da iniciativa privada (Regime de Concessões). Criou-se, com essa lei, a ANP e o CNPE. A União permaneceu com a propriedade das riquezas minerais existentes no território brasileiro.

No Regime de Concessões, o Estado outorga às empresas petrolíferas o direito de realizar as atividades de exploração e produção $(\mathrm{E} \& \mathrm{P})$ em uma estipulada área ofertada ou licitada, por um tempo definido, sob o seu próprio risco. E, em caso de sucesso na exploração, a empresa adquire a propriedade do óleo extraído, bastando apenas compensar o Estado com os devidos pagamentos de royalties e participações especiais.

Os royalties representam compensação financeira devida pelos concessionários ao proprietário da área onde ocorre a atividade de E\&P a partir do início da produção comercial de cada campo.A participação especial, por sua vez, corresponde à compensação financeira extraordinária devida apenas nos casos de grande volume de produção ou de grande rentabilidade.

Com a Lei do Petróleo, surgiu uma determinação de que parte dessesroyalties do petróleo fosse destinada para ciência, tecnologia, pesquisa, desenvolvimento e inovação. Essa determinação possibilitou a criação do Fundo Setorial do Petróleo (CT-Petro), administrado pela Financiadora de Estudos e Projetos (Finep), fundamental para o financiamento de grandes projetos e para a formação de estudantes em diversos níveis de escolaridade. (IBP, 2015)

Também com a descoberta e o anúncio de novas reservas do pré-sal, em meados dos anos 2000, segundo o Instituto Brasileiro do Petróleo (IBP, 2015), o governo brasileiro viu a necessidade de avaliar um novo marco regulatório para a exploração e produção dessas reservas. Na época, a indústria considerou que não havia necessidade de mudança no regime de concessão para administrar a exploração dessa área, sugerindo ajustes ao modelo de concessões existente para contemplar a nova realidade do pré-sal (IBP. 2015). O governo, entretanto, em sua avaliação, optou pela criação de um novo modelo de partilha de produção. 
Assim, segundo Pacheco (2021), em 2010, foi publicada a Lei No. 12.276 que autorizou a união a ceder onerosamente (criou o Regime de Cessão Onerosa) à Petrobras o exercício das atividades de pesquisa à lavra de petróleo, até o limite de produção de cinco bilhões de barris equivalentes de petróleo, em áreas do pré-sal e outras áreas consideradas estratégicas.

Também em 2010, foi criada a empresa pública denominada Empresa Brasileira de Administração de Petróleo e Gás Natural S.A - Pré Sal Petróleo S.A (PPSA), com a finalidade de gerir os contratos de partilha de produção celebrados pelo Ministério de Minas e Energia. A instituição do Regime de Partilha para exploração e produção de petróleo nas áreas do pré-sal e nas áreas estratégicas ocorreu em 22 de dezembro de 2010, quando foi publicada a Lei No. 12.351. Essa lei definiu que a Petrobras deveria liderar todo o investimento na área, com ao menos $30 \%$ de participação nos desembolsos e ainda criou o Fundo Social, com a finalidade de constituir fonte de recursos para o desenvolvimento social e regional, através de programas sociais, direcionando recursos antes direcionados à ciência, tecnologia, pesquisa, desenvolvimento e inovação para o setor social, em especial educação e saúde. A alíquota dos royalties para os contratos de partilha da produção foi definida somente em 30 de novembro de 2012, quando foi publicada Lei No. 12.734. Essa lei estabeleceu o percentual de $15 \%$ e definiu novas regras de distribuição entre os entes da federação dos royalties e da participação especial provenientes da produção de petróleo. (PACHECO, 2021)

O Contrato de Partilha de Produção é assinado entre uma empresa petrolífera ou um consórcio de empresas (seja a Petrobras em contratação direta, ou com a Petrobras sendo operadora com sócios não operadores) e o Estado, seja diretamente com a União ou através da Empresa Estatal de Petróleo. Neste tipo de contrato, o Estado é dono do petróleo produzido - ao contrário do Regime de Concessão onde a propriedade é somente das empresas concessionárias. Dessa forma, o Estado entra com a área a ser explorada enquanto o consórcio conduz as atividades de exploração e produção a seu próprio risco e custo. (PACHECO, 2021)

Assim que as reservas são dadas como comercializáveis, sucede-se a divisão do petróleo produzido. Ou seja, a Empresa Estatal de Petróleo ou agência governamental pertinente recebe sua parte da produção em espécie, possibilitando a comercialização direta no mercado interno ou a promoção de projetos internos.

Segundo o IBP (2015), uma característica do contrato de partilha no Brasil é a existência da figura do operador único, a Petrobras (conforme preconizado na Lei No. 12.351, que instituiu o Regime de Partilha e estabeleceu 30\% de participação da Petrobras 
nos investimentos). $\mathrm{O}$ volume de investimentos em exploração e produção em áreas do présal é extremamente elevado. Diante da diversidade de projetos e de operações nesta área, e considerando ainda a necessidade de enormes aportes de recursos, o IBP passou a defender a ideia de que a concentração da operação em uma única empresa poderia limitar o ritmo de avaliação do potencial exploratório do pré-sal, e do desenvolvimento da produção. Assim, oIBPpassou a defender um cenário de múltiplos operadores, onde haveria maior competição, aumento dos investimentos e mais incentivos à inovação em indústrias de tecnologia de ponta, tornando as atividades de E\&P ainda mais eficazes na província do pré-sal.

Em setembro de 2016, segundo Colombini (2020), o governo de Michel Temer sancionou a MP 727, instituindo o PPI (Programa de Parcerias de Investimentos) e resgatando a Lei $n^{\circ}$ 9.491/1997, que trata do Programa Nacional de Desestatização. Em novembro do mesmo ano, foi aprovado no Senado o PL 4.567/2016 construída pelo senador José Serra, que acabou com a prerrogativa da Petrobrás de ser operadora única dos campos do pré-sal. Por sua vez, a Resolução CNPE nº 07, de 11 de abril de 2017, definiu o novo modelo de conteúdo local a ser aplicado nas rodadas de licitação a partir de então. Além de o percentual de conteúdo local deixar de ser considerado como fator de pontuação das ofertas, houve simplificação dos compromissos e redução dos percentuais mínimos exigidos.

Segundo o referido autor, foi sob esse novo marco regulatório e institucional que o governo passou a estimular a entrada de empresas internacionais nos campos de petróleo do pré-sal, seja como detentoras de reservas, seja como operadoras dos campos. O que estava em jogo não seria apenas a entrada das grandes petroleiras, mas também a garantia da vinculação do petróleo brasileiro nos mercados financeirizados em dólar e dentro dos padrões industriais e tecnológicos ditados pelas gigantes para-petroleiras. Isso implicou numa derrota geopolítica do Brasil, destruindo seu esforço para construção de uma indústria nacional do setor

A partir desse cenário, a Petrobras optou por abandonar várias áreas de negócios e, já sem fôlego para investimentos como operador líder, decidiu não atuar em toda a cadeia produtiva, e passou a priorizar o segmento upstream do pré-sal. Isso provocou o enfraquecimento das políticas de Conteúdo Local com graves impactos nos setores metalmecânico e naval em diversas regiões do país, mas, em especial no Estado do Rio de Janeiro. Um dos caminhos encontrados para minimizar os impactos dessa decisão foi abrir espaço para que outras petroleiras atuassem no Brasil e resgatassem a indústria fornecedora que passou a ser fortemente abatida pela crise. 


\section{INSTABILIDADE NO CENÁRIO SOCIOECONÔMICO E POLÍTICO NO BRASIL A PARTIR DE 2014}

A partir da compreensão da evolução da indústria do petróleo e gás natural e do novo marco regulatório e dos regimes de exploração e produção de petróleo no Brasil, pode-se passar à análise do cenário socioeconômico e político no Brasil a partir de 2014.

O primeiro ponto de análise é o conceito de Conteúdo Local, que é a proporção dos investimentos nacionais aplicados em um determinado bem ou serviço, correspondendo à parcela de participação da indústria nacional na produção desse bem ou serviço. Assim, quando uma plataforma ou refinaria, por exemplo, possui um alto índice de conteúdo local, significa que os bens e serviços utilizados em sua construção são, em grande parte, de origem nacional, e não importados. (PACHECO, 2021)

Segundo o referido autor, desde a primeira Rodada de Licitações, ocorrida em 1999, a ANP estabeleceu requisitos mínimos de Conteúdo Local em seus contratos de concessão com as operadoras vencedoras, para investimentos realizados nas fases de exploração e desenvolvimento da produção.

A cláusula de Conteúdo Local destes contratos estabelecia que fosse dada preferência à contratação de fornecedores brasileiros sempre que suas ofertas apresentassem condições de preço, prazo e qualidade equivalentes às de outros fornecedores convidados a apresentar propostas, aumentando, assim, a participação da indústria nacional, em bases competitivas, nos projetos de exploração e desenvolvimento da produção de petróleo e gás natural.

No entanto, conforme comentando anteriormente, com o contrachoque do petróleo de 2014 e com a decisão da Petrobras de não atuar em toda a cadeia produtiva, priorizando o segmento upstream do pré-sal, graves impactos socioeconômicos passam a ser observados, com reflexos diretos nos indicadores de crescimento econômico, como o Produto Interno Bruto (PIB), por exemplo.

O PIB é calculado achando-se a soma de todos os serviços e bens produzidos num período (mês, trimestre, semestre, ano) numa determinada região (país, estado, cidade, continente) e é expresso em valores monetários (no caso do Brasil, em Reais). Trata-se de um importante indicador das atividades econômicas de uma região ou país, para quantificar o crescimento econômico.

O Gráfico 2 abaixo mostra o comportamento do PIB (PIB a preços de mercado - Taxa acumulada - em \% - em trimestres) no Brasil, de 1997 (ano da aprovação da Lei do Petróleo) a 2020. 
Ao se analisar a evolução temporal do PIB no Gráfico 2, observa-se que o Brasil apresentou um período de taxas decrescentes do PIB de 1997 até 1999, época em que se inicia a aceleração da produção de petróleo em águas profundas na Bacia de Campos. A partir de então, inicia-se um período com taxas voláteis, mas sempre positivas, culminando com o pico de $6,1 \%$ em 2007.

Em 2008 e 2009, observa-se que ocorreu uma forte queda do PIB, em função, em grande parte, da crise do subprime que teve início nos Estados Unidos em 2008, em decorrência da queda das linhas das carteiras de investimentos provocada pelo crescimento da globalização, promovendo um aumento do número de desempregados no país, que não puderam arcar com seus empréstimos assumidos, principalmente da rede bancária, criando uma "bolha imobiliária" que, ao se romper, promoveu um efeito cascata negativo em todos os grandes centros econômicos e financeiros do mundo, incluindo o Brasil.

Gráfico 2 - PIB a preços de mercado - Taxa acumulada (em \%) em trimestres - 1997 a 2020

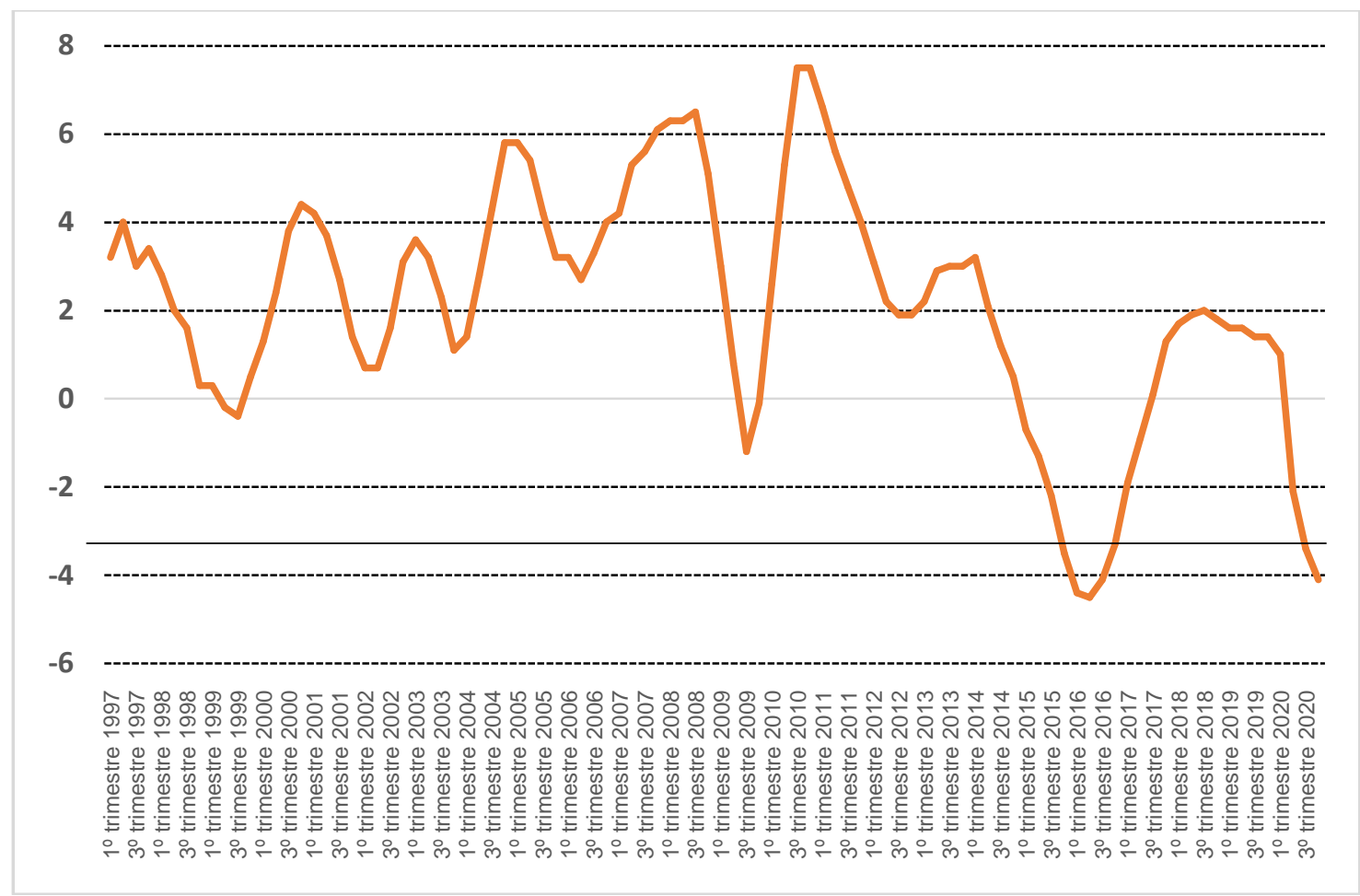

Fonte: IBGE (2021)

Em 2010, observa-se uma forte recuperação, mas seguida por queda em 2011 e 2012. Esta queda reflete a retração do consumo e da produção no país frente aos cenários internacional e macroeconômico instáveis no período pós crise do subprime. 
Em seguida, observa-se uma leve recuperação em 2013, mas novamente com forte queda em 2014 até o início de 2016, atingindo nestes anos valores negativos que significam retração da economia.

Esta queda a partir de 2014 se deve a diversos fatores, com destaque para a instabilidade de fatores correlatos à geopolítica do petróleo e do contrachoque do petróleo e para a instabilidade política com a operação Lava Jato (ROSSI e MELLO, 2017). Esse cenário trouxe à tona o endividamento da Petrobras, que optou por reduzir investimentos em toda sua cadeia produtiva, afetando fortemente o processo de desenvolvimento no país baseado fortemente na política de Conteúdo Local.

Em 2015, o cenário socioeconômico nacional se agrava em função do aumento da instabilidade política provocada pelo desenvolvimento da investigação criminal denominada operação Lava Jato. Em 2016, ocorre a crise do impeachment da presidente Dilma Rousseff. Neste ano, a retração continua, mas reverte a tendência de queda da taxa. Em meados de 2017, o País apresenta sinais de recuperação com índice positivo de crescimento do PIB, ainda que com taxas muito abaixo do esperado. Mas, em 2020, o PIB volta a ficar negativo com o início da crise do COVID-19.

Para se entender esse complexo cenário socioeconômico e político pós 2014 no Brasil, faz necessário analisar de forma mais aprofundada um conjunto de causas concomitantes: a crise internacional do petróleo (contrachoque), o desenvolvimento da investigação criminal denominada operação Lava Jato e a crise política brasileira que culminou com o impeachment da Presidente Dilma Rousseff, e os reflexos dos impactos desses fatores sobre a Petrobras.

\subsection{O contrachoque do petróleo em 2014}

O contrachoque do petróleo de 2014 não foi instantâneo. Desde a crise do petróleo em 1973 o petróleo se tornou mais volátil do que os preços da maioria das outras commodities (REGNIER, 2007 apud BRITO, 2018). Nas três últimas décadas, na maior parte do tempo, o preço do barril operou abaixo dos US\$ 60, exceto no final da década de 1970 e início dos anos 1980, após a revolução no Irã e a guerra Irã-Iraque, e entre 2005 e início de 2014 (com uma depressão em 2008 em função da crise do "subprime" americano). O gráfico 3 ilustra estas variações a partir dos anos 2000. 
Gráfico 3 - Gráfico da evolução do Preço do Barril do Petróleo em US\$

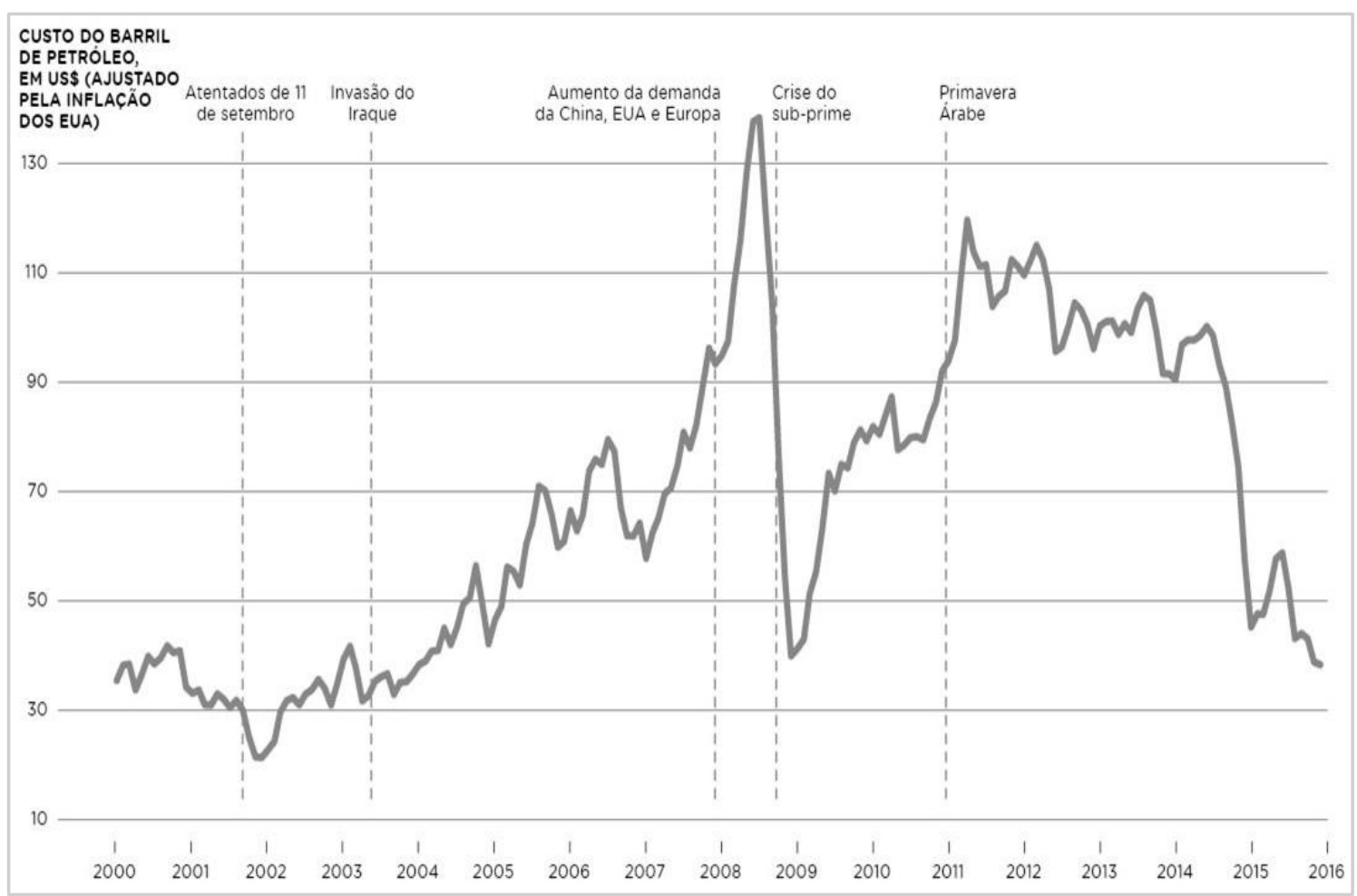

Fonte:Fonte: EPE, 2018 apud Furtado (2019)

Antes da crise do subprime americano, em julho de 2008, o preço do barril de petróleo atingiu um dos últimos picos, chegando próximo dos US\$140. Em seguida, o preço caiu, desta vez abaixo do patamar de US\$ 60, e iniciou uma recuperação até meados de 2011 (ano da Primavera Árabe). Após algumas variações oriundas de acontecimentos geopolíticos, o preço atingiu, em março de 2012, o valor de US\$ 124,93, sustentado até então como o último pico de preço do petróleo, que seguiu oscilando, com leves declínios, até 2014 (PESSANHA, 2017).

Em junho de 2014, ainda era cotado por volta de US\$111,87, mas desta data em diante, o preço do barril de petróleo seguiu caindo no mercado internacional, chegando ao mínimo de US\$ 48,42 em janeiro de 2015 (PESSANHA, 2017) e, em seguida, ao mínimo de US\$ 27 em fevereiro de 2016.Essa queda do valor do barril do petróleo no mercado internacional se caracteriza como uma das maiores crises da história do petróleo.

Após essa depressão, o preço do petróleo iniciou um processo de alta em 2017, ficando num patamar, oscilando em torno de US\$ 60 a US\$ 70 o barril, até cair novamente no final de 2019 e início de 2020, com o início da crise provocada pela pandemia do COVID 19.

Em que pese a volatilidade do valor do petróleo a partir dos anos 70, para compreender o contrachoque de 2014, faz-se necessário analisar mais detalhadamente o 
período que antecede o contrachoque, num recorte temporal sugerido por Ribeiro et al. (2018), que vai de 2010 a 2015.

\subsection{A oscilação no preço do petróleo e o papel exercido pelas forças da oferta e demanda}

Ribeiro et al. (2018) corroboram com Pessanha (2017) no que se refere à volatilidade do preço do petróleo a partir dos anos 1970, e destacam a reversão da tendência de alta e a queda abrupta no preço médio do barril de petróleo, particularmente entre 2014 e 2015 . Nesse período, segundo Ribeiro et al. (2018), o preço do petróleo apresentou o maior declínio já registrado em termos de dólares e a maior queda percentual desde 1986. Em virtude da queda expressiva no valor do barril em um intervalo tão curto de tempo, tal fenômeno foi cunhado de 'contrachoque no preço do petróleo'.

Isenmann (2014) apud Ribeiro et al. (2018) acrescenta que a alta nos preços do petróleo, particularmente entre 2010 e começo de 2014, estimulou a produção não convencional, sobretudo nos Estados Unidos e no Canadá. O governo norte-americano incentivou fortemente a produção "não convencional" de petróleo (shalegas), em especial por meio do fracking ou "hydraulicfracturing" (fraturamento hidráulico), a qual apresentava maiores custos em comparação aos métodos convencionais. Apesar de apresentarem custos de produção mais elevados, os métodos não-convencionais alcançaram viabilidade econômica em um cenário de alta nos preços do barril do petróleo.

Outro aspecto, ainda segundo Ribeiro et al. (2018), que deve ser mencionado aqui para explicar o contrachoque do petróleo diz respeito ao fato de que a elevação no preço do barril de petróleo a partir do início dos anos 2000 incentivou a produção nos países não pertencentes à Organização dos Países Produtores de Petróleo (OPEP). As localidades principais onde se concentram a produção considerada "não-OPEP" são: América do Norte, países que faziam parte da antiga União Soviética (sobretudo a Rússia) e o Mar do Norte. A produção não-OPEP ocorreu principalmente em áreas nas quais os custos de descoberta e de produção de petróleo eram altos, culminando com uma certa desvantagem destes em relação aos produtores da OPEP, os quais desfrutavam de custos de produção mais baixos (EIA, 2016 apud RIBEIRO et al., 2018).

Portanto, segundo Ghirardi (2014) apud Ribeiro et al. (2018), a alta no preço do petróleo até o início de 2014 provocou um excesso de oferta de petróleo no mundo, provocando "sobra" desse recurso no mercado. Como resultado, iniciou-se uma disputa entre 
os grandes produtores de petróleo para garantir seu volume de vendas. Paralelamente a esse processo, houve um esfriamento da procura em decorrência do desaquecimento da economia mundial pós-crise de 2008 e da crônica fragilidade econômica mundial. A China, por exemplo, apesar de ter mantido seu dinamismo nos primeiros momentos da crise, mostrou-se, posteriormente, fragilizada, apresentando uma queda em sua demanda por petróleo.

A desaceleração da economia global reduziu a demanda por petróleo, provocando queda nos preços em um ritmo veloz e deixando o mercado mundial em um momento delicado. A estratégia da OPEP foi um dos fatores que pesaram na cotação dos preços internacionais do produto. Responsável por $40 \%$ do petróleo mundial, a OPEP decidiu, ao fim 2014, não reduzir a produção, objetivando a defesa de sua participação no mercado, já que vinha perdendo espaço para a produção do gás não convencional (shalegas) dos Estados Unidos.

Devido à manutenção de um excesso de oferta, foram gerados excedentes significativos diante da demanda ligeiramente declinante no mundo (PIQUET; HASENCLEVER; SHIMODA, 2016; PESSANHA, 2015). Cabe destacar também que as refinarias de petróleo ao redor do mundo aumentaram a capacidade de refino, em especial na China, e também contribuíram para o aumento da capacidade global acima do crescimento da demanda.

Assim, a maior produção associada à diminuição no consumo provocou uma readequação na curva de oferta e demanda forçando os preços na direção do contrachoque atual. Portanto, segundo Ribeiro et al. (2018), os mecanismos de mercado se mostraramcomofatores relevantes para a análise volatilidade no sistema de preços do petróleo. Entretanto, não são suficientes para um diagnóstico minimamente conclusivo sobre as causas das oscilações no sistema de preços do mercado de petróleo. Faz-se imprescindível, segundo os referidos autores, considerar conjuntamente os fatores geopolíticos e a financeirização do petróleo

\subsection{A geopolítica do petróleo}

Segundo Colombini (2020), as análises históricas sobre o petróleo carecem de um aprofundamento nas distintas formas conceituais de tratar o tema e as complexas vertentes possíveis da disputa geopolítica. As análises com relação aos determinantes do preço do petróleo, segundo o referido autor, tendem a um certo reducionismo economicista, em que ou os fatores de demanda ou de oferta (e produção) se tornam o objeto único de debate. Dessa 
forma, acaba-se por desconsiderar elementos constitutivos da disputa geopolítica pelo petróleo, não apenas em seus termos financeiros, mas como a geopolítica do petróleo faz parte da própria constituição das relações capitalistas internacionais, assim como dos monopólios financeiros e tecnológicos hegemônicos.

Colombini (2020) corrobora com Ribeiro et al. (2018), quando este afirma a importância da compreensão da geopolítica do petróleo para a compreensão da volatilidade do preço do petróleo. Para o referido autor, para além da busca pela sustentabilidade da matriz energética, encontra-se um emaranhado de objetivos estratégicos, políticos, econômicos e de soberania dos Estados nacionais que influenciam o preço do petróleo. A ascensão do petróleo como um recurso revolucionário, estratégico e vital criou uma interligação entre o domínio energético e a concretização do poder no cenário internacional.

Os primórdios da indústria mundial do petróleo, especialmente após a $2^{\mathrm{a}}$ Guerra Mundial, têm um caráter oligopolista, formado por grupo formado por petroleiras norteamericanas e europeias, o chamado cartel das "Sete Irmãs"3. A partir dos anos 1950, os países consumidores e os países detentores das reservas de petróleo exploradas por concessão por essas majors começaram a se mobilizar contra a política de apropriação da renda petrolífera promovida pelo cartel. Além disso, as políticas de autonomia nacional provocaram mudanças nas decisões governamentais. De modo complementar, em 1960, com a finalidade de também enfrentar as majors e de exercerem protagonismo na definição do preço do petróleo no mercado internacional, cria-se a OPEP. (RIBEIRO et al., 2018)

Assim, segundo os referidos autores, até os anos 1970, houve uma onda de nacionalização do petróleo, com o surgimento de companhias nacionais. O petróleo se transformou em elemento central nas estratégias do desenvolvimento de regiões que disfrutavam da presença de grandes reservas. O fim do padrão dólar-ouro e o colapso do sistema Bretton Wood, também no início dos anos 1970, juntamente com a explosão dos preços do petróleo em 1973 impuseram um grande endividamento em dólar aos países, que levou à formação de vultuosos montantes de petrodólares, que contribuíram para a crise do sistema de produção em massa.

Segundo Colombini (2020), com esse novo ordenamento do mercado do petróleo, a partir dos anos de 1980, se intensificaram os debates com duas centralidades específicas para

\footnotetext{
3“O cartel das "Sete Irmãs" era formado pelas "cinco grandes empresas petroleiras norte-americanas em operação no cenário internacional: a Exxon (ou Jersey), a Mobil, a Standard OilofCalifornia (SoCal), a Texaco e a Gulf. Somadas às européias Shell e Anglo-Persian (depois Anglo-Iranian, atual British Petroleum), elas formaram um cartel conhecido como 'As Sete Irmãs', ou majors, que dominou o mercado mundial de petróleo até o início da década de 1970. O que as atraía a operar no exterior eram, sobretudo, os lucros fabulosos proporcionados pela venda do petróleo estrangeiro" (FUSER, 2005, p. 89 apud Ribeiro et al., 2018).
} 
explicar as variações no preço do petróleo, uma mais geopolítica sobre o controle e dominação imposto pelas políticas militar e energética dos EUA, e outra mais voltada a análise de fatores como oferta e demanda do petróleo, especulação pelos mercados financeiros, custos marginais das produções em novos campos, rendas de exploração dos países produtores etc. Neste tópico, será dada atenção especial à questão da geopolítica do petróleo.

A partir dos anos 2000, os Estados Unidos continuaram a exercer um papel de protagonismo na geopolítica internacional. Eles não apenas continuaram como os maiores consumidores de energia do mundo, como também começaram a emergir como os maiores produtores na atualidade, implicando numa redução da dependência do petróleo importado.

Colombini (2020) afirma que esse protagonismo não pode ser completamente compreendido sem entender a importância das para-petroleiras americanas, que fornecem máquinas, materiais e serviços para as petroleiras, na cadeia produtiva do petróleo. Elas são determinantes no desenvolvimento de tecnologias para o setor, controlam um grande número de patentes tecnológicas, ocupam uma posição estratégica global em praticamente todos os países produtores de petróleo, e controlam uma parte importante da cadeia do petróleo no mundo, ajudando na manutenção da hegemonia norte americana nas diretrizes energéticas e tecnológicas do mundo.

Entre 2010 e 2015, observou-se uma certa estabilidade em relação ao consumo de petróleo e, ao contrário, no que se refere à produção, já com predominância do fracking, observou-se um crescimento no volume de produção. (RIBEIRO et al., 2018)

Num cenário de aumento da concorrência por mercados, os países-membros da OPEP promoveram uma mudança de política em 2014, para defender sua fatia de mercado ante os produtores concorrentes de alto-custo, dentro dos quais se enquadram os do xisto americano. Essa mudança vai contra a política de cortes na produção para dar suporte aos preços, ou de ajuste da produção ao mercado para a estabilização dos preços. Diante da desaceleração da demanda chinesa e do crescimento acelerado da produção de gás e óleo de xisto nos Estados Unidos, os países-membros da Opep começaram a extrair petróleo em quantidades recordes, o que forçou a baixa dos preços e tornou o futuro da indústria do xisto incerto

Nesse sentido, além de considerar o aumento da oferta e a redução da demanda a partir de 2014, é preciso que se leve em conta o papel desempenhado pelos principais governos nacionais concorrentes, com destaque para a Arábia Saudita e a Rússia.

Pessanha (2015) corrobora com a ideia de que a liderança da Arábia Saudita entre as nações produtoras de petróleo da OPEP, e a boa relação da Rússia com várias nações fora da 
OPEP, possuem condições de juntos definir o tamanho da oferta do petróleo, influenciando e dirigindo os preços do produto.

A Arábia Saudita é o país que produz o petróleo mais barato e de melhor qualidade no mundo. Para prevenir que o petróleo chegasse a patamares excessivamente elevados e viabilizasse fontes alternativas de energia e exploração do mineral em países fora da OPEP, os sauditas assumiram os papéis de referência no sistema de preços e de "ofertante mundial em última instância” (YERGIN, 2014 apud RIBEIRO et al., 2018).

Nesse sentido, o preço baixo buscou minar o desenvolvimento do fracking norteamericano, método cujo custo era mais elevado do que o convencional. Ademais, o barril do petróleo em patamares reduzidos atingiu o Irã, país com o qual a Arábia Saudita mantém uma relação conflituosa (LIMA, 2015 apud RIBEIRO et al., 2018).

A Rússia, por sua vez, possui território extremamente rico em reservas de petróleo e gás natural, criando uma situação de dependência europeia em relação ao País . (RAFAEL, 2013 apud RIBEIRO et al., 2018). Ademais, nas proximidades do território russo, na Ásia Central, há importantes reservas de óleo e gás natural (RIBEIRO et al., 2018).

Há uma rivalidade histórica entre Rússia e Arábia Saudita que tem se recrudescido nos últimos anos. Enquanto os sauditas têm sido tradicionalmente o coração pulsante da OPEP, a Rússia, desde a União Soviética, sempre esteve de fora do cartel dos países exportadores de petróleo. Além disso, a Arábia Saudita representa um aliado histórico dos Estados Unidos, o que ajudou a atiçar as tensões entre russos e sauditas. Mais recentemente, a Rússia usou sua proximidade geográfica com a China, país cuja demanda por petróleo cresceu significativamente na última década, para a construção de gasodutos até o território chinês, subtraindo assim uma quota do mercado da Arábia Saudita. E também, mais recentemente, os dois países assumiram lados opostos na guerra civil da Síria. Enquanto a Arábia Saudita, Estados Unidos e Turquia apoiam as forças oposicionistas, Rússia e Irã, o regime de Bashar al-Assad (HALLIGAN, 2016 apud RIBEIRO et al., 2018). Esses e outros elementos concernentes à geopolítica do petróleo ajudam a compreender a manutenção da produção russa em patamares elevados, não obstante a queda no preço do petróleo.

É importante frisar que a atual queda do preço do barril atingiria outros adversários dos EUA, além da Rússia, tais como Irã e Venezuela (RIBEIRO et al., 2018). A recusa da Arábia Saudita em diminuir a produção e evitar a queda do preço do petróleo é ratificada por Ghiraddi (2015) apud Bastos, Rosa e Pimenta (2016), pois a queda do preço poderia desestabilizar seu rival Irã, liberado do embargo econômico, testar a resistência das novas indústrias de xisto americanas e forçar a saída de alguns possíveis concorrentes do mercado 
ou causar o adiamento de seus projetos de alto custo. Issoainda, segundo Pessanha (2015), testaria o ponto de equilíbrio do petróleo produzido no pré-sal brasileiro.

Todo esse cenário geopolítico complexo, que manteve a oferta elevada de petróleo em contrapartida da queda da demanda, apresenta-se como pano de fundo para o contrachoque do petróleo em 2014. A partir desse contrachoque, as empresas do setor petrolífero iniciaram um processo de profunda reestruturação. Os investimentos foram reduzidos drasticamente em todo o mundo. As petroleiras colocaram à venda alguns de seus ativos para reduzir a relação entre valor do patrimônio e seus endividamentos. Além disso, as petroleiras reduziram, ao mínimo possível, as perfurações e a busca de novas reservas de petróleo e gás, provocando uma redução no volume mundial de reservas provadas. Também pressionaram suas contratas (para-petroleiras), fornecedoras de materiais, tecnologias e serviços, a reduzirem seus valores de contratos, sob o risco de suspensão dos mesmos. Fusões, incorporações e aquisições foram feitas entre estas empresas desta cadeia produtiva a partir de 2014. Assim formaram-se oligopólios e enormes corporações, com o objetivo de enfrentar menores receitas, naturais na fase de colapso de preços do petróleo, mas com capacidade de determinarem o preço do petróleo no mercado internacional (PESSANHA, 2015). Desarticulava-se, assim, a política de Conteúdo Nacional da cadeia produtiva do petróleo, mola propulsora do desenvolvimento brasileiro.

\subsection{A financeirização do petróleo}

Segundo Ribeiro et al. (2018), desde a década de 1970, o mercado financeiro passou a ter influência crescente sobre os preços da commodity petróleo. No início do processo, denominado pela literatura de financeirização do petróleo, havia uma relação estreita entre o dólar e o petróleo, período no qual os preços desse recurso variavam inversamente com o valor da moeda norte-americana. Durante os períodos de turbulência econômica os agentes buscavam segurança recorrendo ao dólar. No entanto, quando a crise atingia a própria moeda norte-americana, a corrida era em direção às commodities, especialmente ao petróleo, o qual era visto como uma forma de proteção contra a fragilidade do dólar e contra os riscos de inflação. Desse modo, enquanto o valor do dólar caía em comparação a outras moedas, o do petróleo subia, devido à enorme demanda que caracterizava seu mercado (YERGIN, 2014 apud RIBEIRO et al., 2018). Nesse aspecto, o fim da conversibilidade do dólar e adoção do regime de câmbio flutuante e, consequentemente a derrocada do sistema de Bretton Woods, 
deram ensejo à financeirização que caracteriza o capitalismo contemporâneo (SERRANO, 2005 apud RIBEIRO et al., 2018).

Ainda segundo Ribeiro el al., (2018), cumpre ressaltar uma alteração importante no mercado de petróleo em relação ao que ocorria no passado, quando a OPEP representava figura central no processo de fixação do preço do barril de petróleo. Desde 1987, tal organização não mais tem essa função, o que facilitou e/ou permitiu que o processo de financeirização ocorresse na prática nesse mercado. No bojo desse processo, a comercialização de contratos futuros ${ }^{4}$ de petróleo vem crescendo desde então.

Segundo Colombini (2020), nos primeiros anos da década de 1980 foram criados os mercados futuros de petróleo e seus derivados. A International Petroleum Exchange, atualmente ICE Futures (desde junho de 2005), foi criada em Londres em 1980, tendo contratos futuros e de opções, consolidando o Brent como o principal balizador do petróleo no mundo, assim como sua cotação e transação em dólar.

Assim, os anos 1980 marcam o início da realização de contratos futuros envolvendo petróleo. Desde então, a realização de negócios apoiados em derivativos de petróleo vem crescendo continuamente. No início de 2018, pode-se dizer que já exista para cada barril "físico" de petróleo negociado o volume de 18 barris "de papel" no mercado de futuro. (Ribeiro et al., 2018)

Assim, segundo Ribeiro et al. (2018), não é de se estranhar a volatidade do preço de uma commodity cujo mercado é extremamente suscetível a questões geopolíticas e alterações bruscas na oferta (atrelada a novas descobertas como o pré-sal brasileiro, controle da oferta por parte dos países da OPEP e desastres naturais paralisando a produção em reservatórios em alto mar). As incertezas em torno das cotações futuras representam terreno fértil à demanda especulativa no mercado futuro, visto que o especulador toma decisões no presente a partir da previsão que faz sobre a escassez ou abundância no futuro, utilizam estratégias de arbitragem de preços para alcançar o maior lucro possível em suas operações. Nesse contexto, com o aumento da demanda especulativa no mercado futuro, cria-se um cenário no qual o mercado a vista, ou seja, o preço do petróleo a vista, passa a sofrer influência dos movimentos no mercado futuro.

\footnotetext{
${ }^{4}$ Um contrato futuro é o compromisso de comprar e/ou vender determinado ativo em uma data específica no futuro, a preços previamente estabelecidos. Eles são negociados em bolsas organizadas e tem suas características padronizadas por essas associações. Esse tipo de contrato pode ser utilizado com o intuito de reduzir riscos de compra e/ou venda de produtos (ou ativos) que possuem alta volatilidade em seus preços, a fim de evitar ou diminuir perdas. Além disso, um contrato futuro também pode servir como meio de especulação, aumentando a exposição ao risco na expectativa de obter lucros (MENDES, 2003 apud Ribeiro et al., 2018).
} 


\subsection{Crise política no Brasil e a operação "Lava Jato"}

Influenciado pelo complexo cenário geopolítico, pela financeirização do petróleo, e seus impactos na oscilação do preço do petróleo no mercado internacional, o cenário socioeconômico do Brasil se agrava em função de uma grave crise política, tornando ainda mais instável o cenário de atuação das empresas petrolíferas que exercem suas atividades no país.

O agravamento do cenário político se deveu a sérios problemas administrativos de desvio de verbas na Petrobras, com participação de políticos, apuradas pela Operação Lava Jato.

A operação Lava Jato, que deflagrou sua fase ostensiva em 17 de março de 2014, conduzida conjuntamente pela Polícia Federal e Ministério Público Federal, levou à descoberta de desvios em contratos da Petrobras. Tais irregularidades foram cometidas a partir do beneficiamento de certas empresas em contratos de licitação, os quais eram supervalorizados para arcar com os "custos-adicionais" do pagamento de propina a políticos e funcionários da estatal (EBELING, 2016 apud BASTOS, ROSA e PIMENTA, 2016). Esse esquema de corrupção teve grande repercussão no atual contexto econômico-social nacional.

Bastos, Rosa e Pimenta (2016) consideram também, como consequência desta investigação, a crise política vivenciada pelo país, em função de uma ampla investigação envolvendo a Petrobras, empresas privadas que prestavam serviços à companhia e vários políticos. Outras fontes da turbulência política, ainda segundo o referido autor, foram as alegações de irregularidades no financiamento da campanha das eleições presidenciais de 2014 e uma análise do Tribunal de Contas da União (TCU) questionando as contas fiscais do último ano do Governo Dilma Rousseff.

Os reflexos da Operação Lava Jato no mercado financeiro e nos indicadores contábeis da Petrobras no período de 2012-2015, juntamente com os reflexos da crise do petróleo e da crise política, foram graves. A crise do petróleo, de amplitude internacional, teve reflexos severos na saúde financeira de diversas companhias de petróleo do mundo. Contudo, a mais afetada por ela, foi a Petrobras, que perdeu em 2015US\$ 70 bilhões em capitalização de mercado. Parte dessa perda decorre do declínio mundial dos preços do petróleo, mas nenhuma das outras petroleiras no mundo foram punidas tão severamente. (BASTOS ROSA e PIMENTA, 2016) 
Oliveira (2020) complementa que o Brasil tem uma longa história de política industrial e, entre os países ricos em petróleo, implementou uma das mais ambiciosas políticas de conteúdo local, tendo a Petrobras como protagonista.

A política de conteúdo local para a indústria de petróleo e gás teve como objetivo gerar emprego e renda, desenvolvendo a indústria doméstica de suprimentos para o setor. As compras locais de bens e serviços das petroleiras poderiam ter sido utilizadas para alavancar o desenvolvimento econômico.

A política de conteúdo local tem sido um instrumento comum usado por países abundantes em petróleo para canalizar parte do investimento necessário para explorar e desenvolver suas atividades econômicas locais. O Brasil foi um exemplo de país que utilizou essa estratégia de desenvolvimento usar seu know-how de líder global de produção de petróleo em águas profundas pela Petrobras para perseguir objetivos de política industrial (Oliveira, 2020). O fortalecimento da cadeia produtiva foi promovido pelo governo federal por meio de um conjunto de medidas específicas de grande efeito para a indústria nacional, sendo a principal delas a Política de Conteúdo Local. (COLOMBINI, 2020)

Existe uma tese ${ }^{5}$ que, em função do crescimento do protagonismo do Brasil na geopolítica do petróleo, em função da grande expressividade dos campos de petróleo do présal, que têm competitividade compatível com os do Oriente Médio com enorme quantidade de petróleo e pressão dos seus reservatórios, o capital internacional avançou sobre as reservas brasileiras desenvolvendo projetos a preços muito acessíveis.

Colombini (2020) complementa que o modelo de desenvolvimento do setor de petróleo e gás baseado na política de conteúdo local se desenvolvia, ao menos potencialmente, de modo contrário as formas vigentes da estrutura neoliberal do petróleo, tanto potencialmente de controle das rendas e da comercialização desse petróleo nos mercados financeiros dolarizados, quanto potencialmente do controle das máquinas e inovações tecnológicas.

Por outro lado, alguns autores (CBIE, 2020) afirmam que a principal crítica à política de conteúdo local, da forma que foi adotada no Brasil, é que por ser mandatória, tendia ao protecionismo industrial e privilegiou a contratação de empresas locais não competitivas. Essa escolha ineficiente aumentou o custo dos investimentos, além de gerar muitos atrasos no cronograma de investimento, por exemplo, do desenvolvimento do pré-sal. A construção de

\footnotetext{
${ }^{5}$ Essa tese também defende a ideia de que a operação Lava Jato foi articulada politicamente para desmontar e desintegrar a Petrobras e a política de conteúdo local, que antes atuava em toda a cadeia produtiva do petróleo, e que resultaria no impeachment da, então, Presidente Dilma Rousseff.
} 
plataformas para campos da Petrobras seguindo política de conteúdo local teve um atraso médio de quase 4 anos por unidade.

Oliveira (2020) corrobora com essa observação e afirma que, mesmo antes mesmo do contrachoque do petróleo de 2014 e das revelações trazidas pela operação Lava Jato, a política de conteúdo local já vinha falhando em cumprir metas e a pressão para revisá-la aumentava. A Petrobras, por exemplo, passou a cancelar contratos com estaleiros que não foram capazes de entregar produtos e serviços no prazo, mesmo com empresas envolvidas na operação Lava Jato, que pagaram subornos para obter contratos. O contrachoque dos preços do petróleo em 2014 aumentou a urgência de revisar os contratos, uma vez que a indústria global de petróleo se viu obrigada a reduzir drasticamente os investimentos, e o escândalo de corrupção facilitou mudanças de política, permitindo-se a remoção da coalizão política que apoiou a implementação dessa política de conteúdo local.

Assim, a partir da crise explicada acima, ainda segundo Oliveira (2020), muitos dos programas foram desmantelados ou severamente cortados a partir de 2017. No início de 2019, alguns dos "campeões nacionais" criados pela política de conteúdo local, como a empresa de sondas de perfuração Sete Brasil e diversos estaleiros nacionais começaram a encerrar suas atividades ou entraram em recuperação judicial, levando a cortes massivos de empregos não apenas na indústria naval, um fator chave alvo da política conteúdo local, mas em diversos setores impactados direta e indiretamente pela cadeia produtiva do petróleo.

\subsection{A crise da Petrobras}

Após a descoberta de petróleo no pré-sal brasileiro, a partir de 2006, abriu-se um horizonte de perspectivas muito positivas para o Brasil. Segundo Furtado (2019), a Petrobras engajou-se, em decorrência dessas promissoras descobertas, em um mirabolante plano de investimentos, o qual não buscou apenas expandir a produção de petróleo bruto, mas também de derivados de petróleo. Em decorrência desse plano, observou-se, a partir de 2005, a ascensão espetacular do volume de investimentos da empresa, que chegou a multiplicar-se por 3,5 somente entre 2005 e 2009. Essa evolução, contudo, não foi correspondida por uma evolução semelhante da produção. Houve, em decorrência, segundo o referido autor, um completo descolamento entre a ampliação do montante dos investimentos da estatal brasileira e o seu nível de produção de petróleo e gás natural. Os investimentos alcançaram, em valores de 2019, 48,8 bilhões de dólares no pico de 2013. Em compensação, a produção de petróleo 
não acompanhou essa evolução, constatando-se, inclusive, uma inflexão negativa da produção, que chegou até a cair no início da presente década.

Ainda segundo Furtado (2019), vários fatores parecem explicar a divergência de comportamento entre o investimento e a produção da Petrobras. O plano de investimentos da empresa não se concentrou apenas no aumento da produção de petróleo bruto, mas também ampliou substancialmente o investimento em novas refinarias. A razão dada à época para expandir a capacidade de refino era que a produção de óleo bruto iria ultrapassar em muito o consumo interno e que seria mais adequado processar esse petróleo para adicionar valor às exportações. A localização das refinarias em estados do Nordeste se justificava porque estariam no caminho do hemisfério norte. $\mathrm{O}$ custo desses investimentos acabou derivando, tornando-os pouco rentáveis. Os investimentos em outras áreas, incluindo-se o refino, gás e energia, internacional, chegou a ultrapassar o investimento no upstream em 2010. Apenas a partir de 2013, os investimentos da estatal brasileira voltaram a priorizar a área de exploração e produção.

Por outro lado, os investimentos no upstream se concentraram nos campos do pré-sal, deixando de lado os campos existentes em águas profundas que estavam alcançando o limite da sua vida útil (FURTADO, 2019). Verificou-se, consequentemente, nos dois primeiros anos da década de 2010 (ver Gráfico 1), uma queda acentuada da produção dos campos maduros da bacia de Campos sem que a nova oferta do pré-sal conseguisse compensá-la. Entretanto, nos anos seguintes, foi graças à rápida expansão da produção do pré-sal que a Petrobras logrou contrabalançar a queda acentuada da produção dos campos maduros no período mais recente.

De acordo com a ANP (2021), a produção de petróleo equivalente do pré-sal alcançou $68,61 \%$ da produção nacional em 2020. Em 2010, essa produção representava apenas 1,53\% do total nacional. Por outro lado, de 2010 a 2020, a produção terrestre saiu de 11,60\% para $5,95 \%$ da produção nacional, e a produção marítima no pós-sal, de $86,87 \%$ para $25,44 \%$ do total do país.

Gráfico 4 - Evolução da Produção de Petróleo no Brasil por Ambiente de Produção 

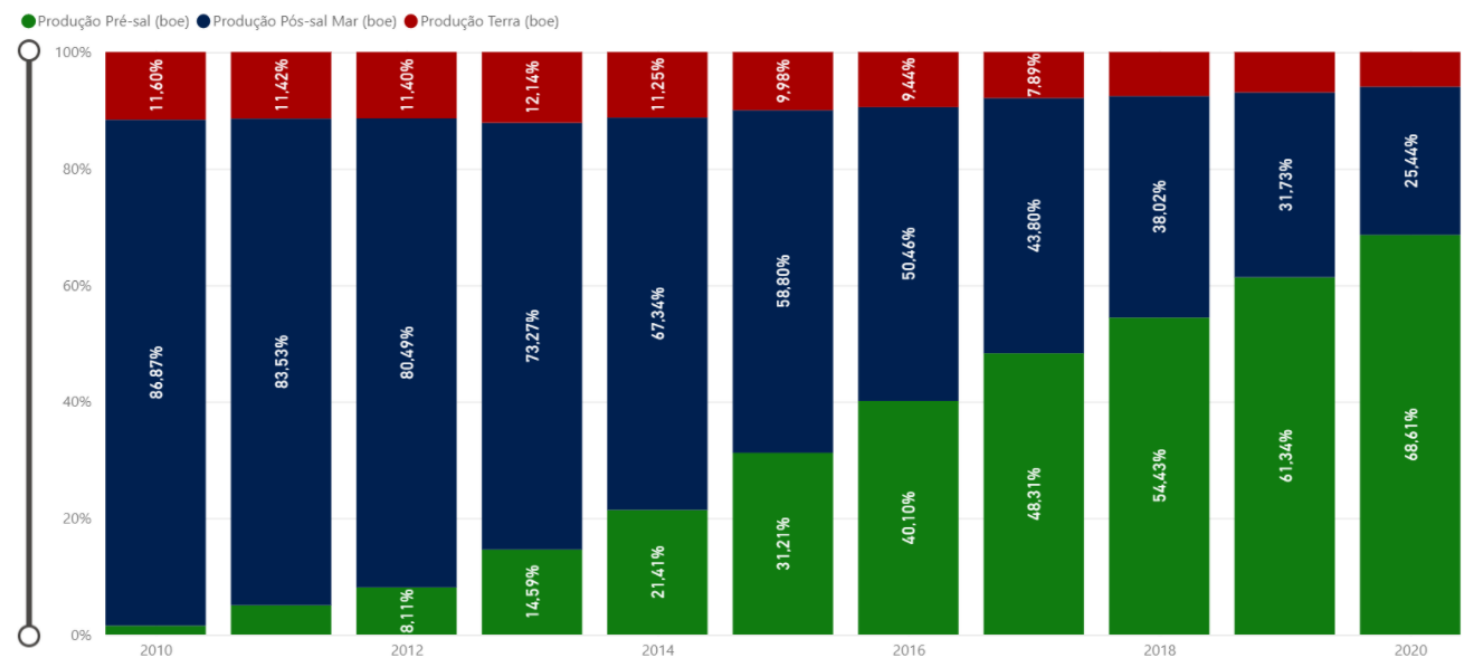

Fonte: ANP (2021)

Para agravar o impacto financeiro dessa inflexão da produção, deve-se salientar que, ainda que a participação da Petrobras como operadora seja predominante no cenário nacional, com $93,7 \%$ e $95 \%$ da produção de petróleo e gás natural do país em 2018, ela é bem inferior enquanto concessionária, $77,8 \%$ e $76,6 \%$ respectivamente, o que se manifesta com maior intensidade nos novos campos do pré-sal. Nesse sentido, a retomada da produção apoiada nesses campos resultou em um menor impacto sobre as receitas da estatal. (Furtado, 2019)

Cabe lembrar que a queda da produção interna de petróleo, nos anos iniciais da década de 2010, ocorreu em um contexto em que a demanda por derivados de petróleo estava em plena expansão. Como foi visto, essa rápida expansão da demanda de derivados decorreu, em parte, do fraco desempenho dos biocombustíveis, principalmente do etanol, e também porque o consumo continuava aquecido em virtude das políticas contracíclicas do governo Dilma Rousseff de expansão da demanda interna e de contenção do preço ${ }^{6}$ dos derivados de petróleo no país. Nesse período, o consumo aumentou acima da oferta interna, obrigando a Petrobras a importar derivados a preços superiores aos do mercado interno. (FURTADO, 2019)

Barbosa Filho (2017) já afirmava, antes de Furtado (2019), que, simultaneamente à elevação na demanda de investimento por parte da Petrobras, houve controle do preço de seus derivados. O controle de preços de combustíveis afetou a Petrobras que vendia gasolina no mercado doméstico a um preço inferior ao que comprava no mercado internacional. Essa política resultou em perdas bilionárias, reduzindo de forma substancial o caixa da empresa.

\footnotetext{
${ }^{6}$ A política de contenção dos preços do GLP, gasolina e do óleo diesel no mercado interno determinada pelo Governo Federal durante o período 2011 a 2014 causou um prejuízo para a Petrobras estimado em R\$ 21,2 bilhões, provocado pelas importações a preços superiores aos do mercado interno (ALMEIDA; OLIVEIRA; LOSEKAN, 2015 apud FURTADO, 2019).
} 
A conjunção de um elevado nível de investimento com a queda da receita, provocada pela queda da produção interna, associada à importação de derivados a preços superiores aos do mercado interno, levou a uma rápida deterioração da situação financeira da Petrobras, que se refletiu em um acelerado processo de endividamento (FURTADO, 2019). Esse endividamento, ainda segundo o referido autor, obrigou a empresa a ter que dar, a partir de 2014, uma guinada profunda em sua estratégia de expansão para garantir sua sobrevivência e evitar a insolvência. As mudanças ocorreram em dois planos. Em primeiro lugar, ela reduziu acentuadamente os investimentos e, por outro lado, concentrou esses investimentos no upstream.

O refino, que tinha recebido especial atenção na fase anterior, teve sua participação reduzida no plano de negócios de 2018-2022. Das quatro refinarias anteriormente projetadas, apenas a refinaria de Abreu e Lima, localizada próxima a Recife, teve continuidade, mas somente foi finalizada parcialmente. O Complexo Petroquímico do Rio de Janeiro (COMPERJ) teve suas obras interrompidas, sem perspectiva de retomada no atual plano de negócios. Por outro lado, os projetos das duas outras refinarias, previstas para serem implantadas nos estados do Maranhão e Ceará, foram abandonados. Adiciona-se a esse recuo dos investimentos, a pretensão do Plano de desinvestimento da empresa de se desfazer das refinarias do Nordeste. (FURTADO, 2019)

Essa guinada da Petrobras se refletiu também em outras áreas como a internacional, biocombustíveis, fertilizantes, petroquímica, gás e energia, distribuição, cujos ativos foram colocados à venda, mas nem sempre se encontraram interessados para a aquisição. (FURTADO, 2019)

Essa alteração de rota da Petrobras surtiu importantes resultados em termos da redução de seu endividamento. Embora essa performance possa ter sido considerada necessária para a sobrevida da empresa, ela implicou em profundas consequências, desfigurando suas características de empresa integrada verticalmente e, sobretudo, diversificada para setores complementares, como geração termoelétrica, petroquímica/fertilizantes, biocombustíveis e energias renováveis (FURTADO, 2019) e provocou graves impactos negativos na política de conteúdo local da cadeia produtiva do petróleo.

Nesse sentido, esses quatro fatores principais, o contrachoque do petróleo em 2014, a oscilação no preço do petróleo em função das forças de oferta e demanda, e a crise política e a operação Lava Jato provocaram uma grave crise na Petrobras, que exigiram um redimensionamento nos investimentos e uma revisão na gestão dos contratos ao longo da 
cadeia produtiva. Como a empresa desempenha um papel proeminente no cenário petrolífero brasileiro, responsabilizando-se por 93,5\% da produção nacional de petróleo e 92,5\% da de gás (ANP, 2020), era de se esperar os impactos socioeconômicos negativos nos municípios e estados produtores e na união.

\section{CONSIDERAÇÕES FINAIS}

Os estudos das forças de oferta e demanda, embora historicamente de grande relevância, mostraram-se insuficientes para explicar a complexidade da volatilidade dos preços do petróleo a partir da $2^{\mathrm{a}}$ Guerra Mundial, commodity estratégica não apenas para autonomia energética das nações, mas também para seu protagonismo na geopolítica internacional.

A geopolítica do petróleo assumiu papel fundamental para a compreensão da volatilidade do petróleo, uma vez o domínio de reservas e da produção passou a significar força e poder político e econômico no cenário internacional. O contrachoque do petróleo de 2014 foi resultado dessa disputa de forças envolvendo interesses diversos de grandes players como EUA, Arábia Saudita, Rússia, dentre outros.

A financeirização do petróleo, a partir dos anos 1980, marcam o início da realização de contratos futuros envolvendo petróleo, interferindo no seu preço à vista, e contribuem para a explicação da volatilidade do preço da commodity.

Esses três fatores compõem parte importante da miríade de fatores que explicam a volatilidade do petróleo (RIBEIRO et al., 2018; COLOMBINI, 2020; FURTADO, 2019).

A instabilidade socioeconômica e política no Brasil a partir de 2014, por sua vez, tem como causas principais, dentre vários fatores, as mudanças no marco regulatório do petróleo no país e a Operação Lava Jato. Mas as mudanças no marco regulatório são resultado de uma grande disputa geopolítica pelo petróleo brasileiro. Esse novo marco regulatório e institucional passou a estimular a entrada de empresas internacionais nos campos de petróleo do pré-sal, seja como detentoras de reservas, seja como operadoras dos campos. Isso implicou numa derrota geopolítica do Brasil, enfraquecendo a política de conteúdo nacional e destruindo seu esforço para construção de uma indústria nacional do setor petróleo.

A Operação Lava Jato, por sua vez, aumentou a urgência de revisar os contratos com as empresas fornecedoras de bens e serviços, uma vez que a indústria global de petróleo se viu obrigada a reduzir drasticamente os investimentos, e o escândalo de corrupção facilitou mudanças de política, permitindo-se a remoção da coalizão política que apoiou a 
implementação dessa política de conteúdo local. Assim, muitos contratos e programas foram desmantelados ou severamente cortados a partir de 2017.

Tais fatores conjugados, por sua vez, influenciaram a crise da Petrobras, obrigando-a a reduzir seu escopo de atuação na cadeia produtiva e, por conseguinte, reduzindo sua capacidade como instrumento propulsor da política de conteúdo local do país, fundamental para o desenvolvimento socioeconômico nacional e das regiões produtoras, em especial o Estado do Rio de Janeiro, maior produtor nacional.

Segundo Colombini (2020), depois de uma década de tentativas, o acirramento das disputas geopolíticas restabeleceu as grandes petroleiras e para-petroleiras internacionais no controle do petróleo brasileiro. O contrachoque do petróleo, junto com a forte instabilidade socioeconômica e política brasileira, possibilitou o retorno e fortalecimento das gigantes internacionais, restabelecendo o controle da produção brasileira (principalmente dos enormes campos do pré-sal) com o domínio da fabricação das máquinas e equipamentos, assim como da pesquisa científica e tecnológica do setor.

Por fim, como sugestão de estudos futuros, faz-se importante analisar os impactos do contrachoque do petróleo e da instabilidade socioeconômica e política no país e, em especial, na maior região produtora de petróleo do país, o Estado do Rio de Janeiro (responsável pela produção de $80 \%$ do petróleo e $61 \%$ do gás nacional produzido no país (ANP, 2021)) e os municípios produtores das Bacias de Campos e de Santos. Sugere-se analisar os impactos na arrecadação de royalties, participações especiaisenas demais arrecadações como ICMS, ISS, dentre outros, os impactos nos estoques de empregos formais e quais setores e ocupações mais eliminaram empregos, os impactos nos índices de desemprego, os impactos nos indicadores de desenvolvimento socioeconômico como Índice de Desenvolvimento Humano (IDH), Índice FIRJAN de Desenvolvimento Municipal (IFDM), Índice de Desenvolvimento Municipal Sustentável (IDMS).

\section{REFERÊNCIAS}

AGÊNCIA NACIONAL DO PETRÓLEO, GÁS NATURAL E BIOCOMBUSTÍVEIS. Superintendência de Desenvolvimento e Produção. Boletim da Produção de Petróleo e Gás Natural. Boletim da Produção de Petróleo e Gás Natural, Rio de Janeiro, n. 125, p. 1-40, 28 fev. 2021. Disponível em: https://www.gov.br/anp/pt-br/centrais-deconteudo/publicacoes/boletins-anp/bmp/2021/2021-01-boletim.pdf. Acesso em: 9 mar. 2021. 
BARBOSA FILHO, F. de H. A crise econômica de 2014/2017. Estudos Avançados, [S. l.], v. 31, n. 89, p. 51-60, 2017. Disponível em: https://www.revistas.usp.br/eav/article/view/132416. Acesso em: 07 abr. 2021.

BASTOS, Emanuelle de Souza; ROSA, Maycon Peter da; PIMENTA, Márcio Marvila. Os Impactos da Operação Lava Jato e da Crise Internacional do Petróleo nos Retorno Anormais e Indicadores Contábeis da Petrobras 2012-2015. Pensar Contábil, Rio de Janeiro, v. 18, n. 17, p. 49-56, 6 out. 2016. Disponível em: http://www.atena.org.br/revista/ojs-2.2.308/index.php/pensarcontabil/article/view/2947. Acesso em: 26 fev. 2021.

BRITO, Flavianne de Souza R. de; GUALBERTO, Andrezza R.; SILVA NETO, Romeu e. Impactos iniciais da crise do petróleo de 2014 nos municípios do Circuito Espacial do Petróleo do Estado do Rio de Janeiro. Anais do XVII ENANPUR: Encontro Nacional da Associação Nacional de Pós-Graduação e Pesquisa em Planejamento Urbano e Regional, São Paulo, p. 1-19, 22 maio 2017. Disponível em: http://anpur.org.br/xviienanpur/principal/?page_id=1360. Acesso em: 16 fev. 2021.

BRITO, Flavianne de Souza Ramos de. Impactos socioeconômicos da crise do petróleo de 2014: uma análise dos índices e indicadores dos municípios petrorrentistas. 2018. 96 p. Dissertação (Mestrado em Engenharia de Produção) - Universidade Cândido Mendes, Campos dos Goytacazes, 2018.

COLOMBINI, Iderley. Crise da geopolítica do petróleo no Brasil e o 'mundo invisível' das para-petroleiras. Oykos, Rio de Janeiro, v. 19, n. 1, p. 122-141, mai/2020. Disponível em: http://revistaoikos.org/seer/index.php/oikos/article/viewArticle/638. Acesso em: 20 mar. 2021.

FURTADO, André Tosi. Indústria do Petróleo e Gás Natural: uma vocação desperdiçada. Cadernos do Desenvolvimento, Rio de Janeiro, v. 14, n. 24, p. 155-175, janjun/2019. Disponível em: http://www.cadernosdodesenvolvimento.org.br/ojs2.4.8/index.php/cdes/article/view/392/pdf. Acesso em: 23 mar. 2021.

INSTITUTO BRASILEIRO DO PETRÓLEO, GÁS E BIOCOMBUSTÍVEIS. A relevância do petróleo e gás para o Brasil. Caderno Técnico do IBP, Rio de Janeiro, ano 2015, p. 1-86, 1 jun. 2015. Disponível em: https://rdstationstatic.s3.amazonaws.com/cms\%2Ffiles\%2F49401\%2F1566244541Publicao_IBP_EYfinal.pdf. Acesso em: 02 fev. 2021.

INSTITUTO BRASILEIRO DE GEOGRAFIA E ESTATÍSTICA (Brasil). Sistema de Contas Nacionais Trimestrais - SCNT: Séries históricas - PIB a preços de mercado - Taxa acumulada em 4 trimestres (\%), $1^{\circ}$ trimestre 1996 - $4^{\circ}$ trimestre 2020. Rio de Janeiro: IBGE, 17 mar. 2021. Disponível em: https://www.ibge.gov.br/estatisticas/economicas/contasnacionais/9300-contas-nacionais-trimestrais.html? $=\& \mathrm{t}=$ series-

historicas\&utm_source=landing\&utm_medium=explica\&utm_campaign=pib\#evolucao-taxa. Acesso em: 17 mar. 2021.

MORAIS, José Mauro de. Petrobras: Crise financeira e de credibilidade e recuperação recente. Radar, Rio de Janeiro, p. 19-23, 1 out. 2017. Disponível em: 
http://repositorio.ipea.gov.br/bitstream/11058/8111/1/Radar_n53_Petrobras.pdf. Acesso em: 28 jan. 2021.

NADER, Glauco Lopes. O posicionamento estratégico de Macaé no desenvolvimento do estado do Rio de Janeiro. 2009. 274 f. Tese (Doutorado) - Curso de Planejamento Urbano e Regional da Universidade Federal do Rio de Janeiro, Pós-graduação, Universidade Federal do Rio de Janeiro (UFRJ), Rio de Janeiro, 2009.

OLIVEIRA, Renato Lima de. Corruption and local content development: Assessing the impact of the Petrobras' scandal on recent policy changes in Brazil. The Extractive Industries and Society, Boston, n. 7, p. 274-282, 2020. DOI https://doi.org/10.1016/j.exis.2019.08.004. Disponível em: https://www.sciencedirect.com/science/article/abs/pii/S2214790X19300747. Acesso em: 15 mar. 2021.

PESSANHA, Roberto Moraes. A ampliação da fronteira de exploração petrolífera no Brasil é parte da geopolítica da energia: oportunidades e riscos de inserção global em meio às novas territorialidades regionais e ao desafio da abundância na economia dos royalties no Estado do Rio de Janeiro. Espaço e economia. [s.1.], n. 6, Ano III, 2015.

PESSANHA, Roberto Moraes. A relação transescalar e multidimensional "PetróleoPorto" como produtora de novas territorialidades. 2017. 560 f. Tese (Programa de Pósgraduação em Políticas Públicas e Formação Humana) - Universidade do Estado do Rio de Janeiro, [S. l.], 2017.

PESSOA, João Monteiro. Ascensão e queda da bacia de Campos: uma análise histórica dos fatores determinantes. 2017. 120 f. Dissertação (Mestrado em Planejamento Regional e Gestão de Cidades) - Universidade Cândido Mendes, Campos dos Goytacazes, 2017.

PIQUET, Rosélia Périssé da Silva; HASENCLEVER, Lia; SHIMODA, Eduardo. O desenvolvimento e a política de conteúdo local na indústria petrolífera: visões divergentes. Revista Tecnologia e Sociedade, Curitiba, v. 12, n. 24, p.1-26, jan./abr. 2016.

PRODUÇÃO de petróleo e gás teve recorde em 2020 e aumentou 52,71\% em relação a 2010. In: AGÊNCIA NACIONAL DO PETRÓLEO, GÁS NATURAL E BIOCOMBUSTÍVEIS. Notícias e Comunicados. Rio de Janeiro, 29 jan. 2021. Disponível em: https://www.gov.br/anp/pt-br/canais_atendimento/imprensa/noticiascomunicados/producao-de-petroleo-e-gas-teve-recorde-em-2020-e-aumentou-52-71-emrelacao-a-

2010\#: :text=Produ\%C3\%A7\%C3\%A3o\%20de\%20petr\%C3\%B3leo\%20e\%20g\%C3\%A1s $\% 20$ teve $\% 20$ recorde $\% 20 \mathrm{em}$, metros $\% 20 \mathrm{c} \% \mathrm{C} 3 \% \mathrm{BAbicos} \% 20 \mathrm{de} \% 20 \mathrm{~g} \% \mathrm{C} 3 \% \mathrm{~A} 1 \mathrm{~s} \% 20$ natural $\% 20$ por\%20dia\%20. Acesso em: 01 mar. 2021.

RIBEIRO, C. G., Alba Neto, H. B., \& Sene, T. S. (2018). A oscilação do preço do petróleo: uma análise sobre o período entre 2010-2015. Estudos Internacionais: Revista de relações Internacionais Da PUC Minas, 6 (1), 87-106. 
ROSSI, Pedro; MELLO, Guilherme. Choque recessivo e a maior crise da históriaA economia brasileira em marcha à ré: A economia brasileira em marcha à ré. Centro de Estudos de Conjuntura e Política Econômica - IE/UNICAMP, São Paulo, 1 abr. 2017. Nota do Cecon, n.1, p. 1-5. Disponível em: https://www3.eco.unicamp.br/images/arquivos/NotaCecon1_Choque_recessivo_2.pdf. Acesso em: 25 fev. 2021.

SANTOS, Ricardo José dos. Políticas de apoio à cadeia da indústria do petróleo e gás no Brasil: um estudo das ações públicas no período 1997-2014. 2015. 180 f. Tese (Programa de Pós-graduação em Economia) - Universidade Federal de Uberlância, Uberlância, 2015. Disponível em: ttps://repositorio.ufu.br/bitstream/123456789/13463/1/PoliticasApoioCadeia.pdf. Acesso em: 29 jan. 